\title{
COVID-19 Mortality Risk Assessment among Various Age Groups Using Phylogenetic Analysis
}

\begin{abstract}
Verma, Pawan ${ }^{1}$, Elkaffas, Rasha ${ }^{*}$, Shodunke, Oluwasefunmi C. ${ }^{3}$, Hrab, Pavlo4, Adebayo, Oluwatobiloba H. ${ }^{5}$, Alam, Humaira Marzia ${ }^{6}$, Gbedema, Wilson ${ }^{7}$, Agbonyin, Mosadoluwa A. ${ }^{8}$, Osman, Ahmed M. ${ }^{9}$, Igbokwe, Joseph 0. ${ }^{10}$, Sudarsanam, Harinath ${ }^{11}$, Adepoju, Ayodeji ${ }^{12}$, Abass, Ohilebo A. ${ }^{13}$, Olorunfemi, Sola R. ${ }^{14}$, Oladejo, Sarah O. ${ }^{15}$, Semilogo, Sonaike ${ }^{16}$, Hurtado, Jairo ${ }^{17}$, Ferdousee, Shahida ${ }^{18}$, Peter, Josiah Aminu ${ }^{19}$, Oluwasanmi, Adetutu D. ${ }^{20}$, Agbaje, Sheriff T.. ${ }^{21}$, Sheen, Alexandra ${ }^{22}$, Sharma, Mukul ${ }^{23}$, Ibitoye, Opeyemi ${ }^{24}$, El-Gammal, Ahmed ${ }^{25}$, Olutunde, Olaleye T. ${ }^{26}$, Krishna, Meera ${ }^{27}$, Ezechukwu, Tracy-allen M.. ${ }^{28}$, Carl, Sarah H. ${ }^{29}$
\end{abstract}

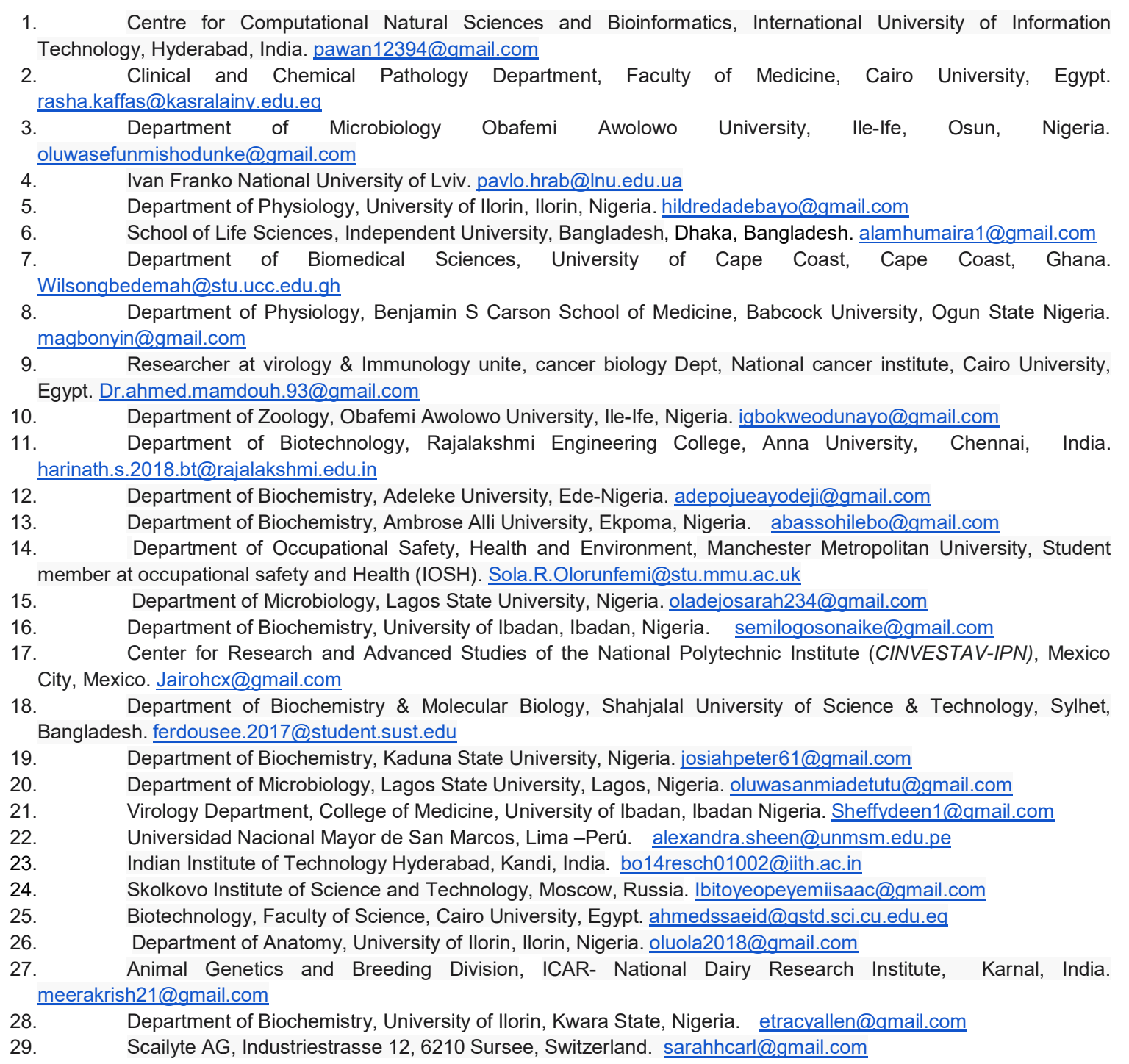

${ }^{*}$ Corresponding author:

rasha.kaffas@kasralainy.edu.eg, https://orcid.org/0000-0001-9375-5100

Correspondance: Rasha Elkaffas. Clinical and Chemical Pathology Department, Faculty of Medicine, Cairo University, Egypt. rasha.kaffas@kasralainy.edu.eg 


\section{ABSTRACT}

The age-related mortality and morbidity risk of COVID-19 has been considered speculative without enough scientific evidence. This study aimed to collect more evidence on the association between patient age and risk of severe disease state and/or mortality from SARS-CoV-2 infection. Genomic dataset along with metadata (3608 samples) retrieved from GISAID from different geographical regions were grouped into 10 age groups $(0-10,11-20$, 21-30, 31-40, 41-50, 51-60, 61-70, 71-80, 81-90, 91-100 years) as well as high-risk or lowrisk according to patient clinical status. Genomic sequences were aligned and analyzed using MAFFT and FASTTREE to build a phylogenetic tree in order to identify age-risk associations based on phylogenetic clustering. Case fatality rates(CFR), as well as the Odds ratio (OR) for high-risk outcomes, were calculated for different age groups. Results revealed that individuals aged between 25-50 years have the best immune response to the infection. On the other hand, disease fatality was higher in patients aging above 50 years. We created an application to calculate the OR of being at high risk given a certain age threshold from GISAID datasets. OR values increased between ages 1-10 years (1.271) and 11-20 years (1.313) but reduced at age range 21-30 years (1.290) and increased again for 61-70 years (2.465). CFR calculated for each of the age groups had peak values at $90-100$ years $(26.8 \%)$ and the lowest at $0-10$ years $(0 \%)$. The CFR for ages above 50 years was about twice greater (11.6\%-26.8\%) than that for ages below (0-6.6\%). The phylogenetic analysis revealed that the majority of samples obtained from India showed low-risk among different age groups and were defined as clade $\mathrm{GH}$. Another cluster from Singapore visualization showed unfavorable patient outcome across several age groups and were classified under clade $\mathrm{O}$. To conclude, this study analyses showed a variety of age-risk associations. As scientists from different countries upload more genomes to globally shared databases, more evidence will reinforce mortality risk associations in COVID-19 patients.

\section{Keywords}

SARS-CoV-2; COVID-19; Phylogenetics; mortality 


\section{BACKGROUND AND INTRODUCTION}

The current coronavirus pandemic that was caused by severe acute respiratory syndrome coronavirus 2 (SARS-CoV-2) is not the first pandemic of the family Coronaviridae [1]. In 2002 and 2012 respectively, severe acute respiratory syndrome (SARS) and middle east respiratory syndrome (MERS) caused by severe acute respiratory syndrome coronavirus (SARS-CoV) and middle east respiratory syndrome coronavirus (MERS-CoV) outbreaks emerged [1][2][3][4][5]. Taxonomically, There are seven coronaviruses namely: 229E ( $\alpha$ ), NL63 ( $\alpha)$, OC43 ( $\beta)$, HKU1 $(\beta)$, MERS-CoV, SARS-CoV, SARS-CoV-2. They belong to the family Coronaviridae and SARS-CoV-2 is a strain of the SARS related coronavirus (SARSr-CoV) that is genetically associated with other coronavirus strains that infect bats in China [6][7]. From its period of emergence up until the end of 2002, coronavirus was considered to be non-fatal [7]. Currently, SARSCoV-2; first isolated in Wuhan China; has led to more deaths than the earlier SARS outbreak of 2002-2003. As of September 7, 2020, it has been responsible for nearly 27 million cases and 900,000 deaths worldwide [8]. Sequenced SARS-CoV-2 genomic data from human hosts available at the Global Initiative on Sharing All Influenza Data (GISAID), identified three major clades of SARS-CoV-2 viz; clade G (a variant of the spike protein S-D614G), clade V (a variant of the ORF3a coding protein NS3-G251), and clade S (variant ORF8-L84S) [9]. Phylogenetic data has grouped the variants into clusters namely; A, B, and C. Both clusters A and C spread more outside of East Asia, mostly in America and Europe. In contrast, type $B$ is the most common variant infecting East Asia, and the ancestor species appears to have never spread outside of East Asia without first converting to the B species [10]. Until this moment, the SARS-CoV-2 has been characterized by mutations, which help explain its origin, distribution, and tracing viral pathogenesis in every continent [11]. For instance, there were 5775 distinct variants out of 10022 SARS-CoV-2 genomes analyzed; of these, 2969 missense mutations, 1965 synonymous mutations, and 484 mutations in the non-coding regions were observed in samples obtained from 68 countries [12]. SARS-CoV-2 belongs to the Betacoronavirus genus, the most prevalent, which shares $82 \%$ nucleotide identity with SARS-CoV and about $50 \%$ with MERS-CoV [13]. Using specialized tools and techniques, researchers have been able to conduct phylogenetic studies of the SARS-CoV-2 genome against suspected zoonotic reservoirs [14][15]. Multiple Sequence Alignment (MSA) of SARSCoV-2 genome data has revealed tremendous amounts of information, including 
evolutionary diversity, and similarity with other coronavirus strains. With the help of Multiple Alignment using Fast Fourier Transform (MAFFT), research has revealed that SARS-CoV and MERS-CoV both originated in bats [16]. In humans, as one age, the potential of the immune system to fight against infections diminishes [17]. Previous studies have suggested that older adults are highly susceptible to SARS-CoV-2 infection and may suffer severe COVID-19 outcomes due to comorbidities [18]. It is still not clear whether age (associated immune decline) has a direct influence on COVID-19 mortality. It is therefore important that we identify whether patient age may affect disease severity and/or mortality rates, and also identify any evolutionary pattern exhibited by the virus as it is transmitted between different hosts across various geographical locations. In this study, we have constructed a maximum likelihood phylogenetic tree of SARS-CoV-2 virus strains collected from different countries the virus has spread its tail. The phylogenetic tree will give us an idea about the strain of the virus that got introduced in a country and how that affects disease severity and/or mortality.

\section{METHODS}

\subsection{Data Download and Filtration}

The clinical dataset of COVID-19 patients and the genomic sequence for each SARSCoV-2 infected patient was collected from the GISAID EpiCoV repository [9]. The retrieved dataset contains a total of 4592 genomes. A Python (v.3.7.4) script (pandas v.1.0.5 [19] and Biopython v.1.77 [20] packages) was used to filter the data, generate FASTA and the clinical dataset files. For the data cleaning, samples corresponding to non-human hosts were filtered out. Additionally, all samples corresponding to unknown and those tagged as Not Available (NA) in the patient status and patient age column were filtered out thereby reducing the dataset from 4592 samples to 3608 samples. The Biopython package was specifically used to parse the FASTA file containing the complete genomic data. All the filtered genomic and clinical data were written to a new file using the python script.

\subsection{Multiple Sequence Alignment and Phylogenetic tree reconstruction} Using the filtered genomic data, multiple sequence alignment was performed using MAFFT (Galaxy v.7.221). MAFFT performs progressive alignment and iterative 
refinement for increased accuracy and aligns as many as 30,000 sequences [21]. To generate the maximum likelihood phylogenetic tree, the FastTree program was used (Galaxy v.2.1.10+galaxy). FastTree generates maximum likelihood phylogenetic trees to find the local optimum or 'best tree' [22]. All the analysis concerning Phylogenetic tree reconstruction was performed on the Galaxy web server [23]. Default parameters were used to perform the analysis using the filtered genomic dataset. MAFFT generated an alignment in FASTA format, which was used as an input to the FastTree program. iToL was used To efficiently visualize the phylogenetic tree, One of the key features of this software is that it allows large trees with large numbers of taxa to be easily visualized, located on the internet, and edited. The public sharing allows the tree to be reused for future analysis [24].

\subsection{Odds Ratio calculations}

To determine whether exposure is a risk factor for a particular risk outcome, a measure of association, Odds ratio (OR), was used to compare the relative odds of the disease outcome with a given exposure to a specific variable of interest (e.g.age) [25]. In this study, the clinical dataset was used to calculate the OR, after being categorized into "Low risk" and "High risk" using R (Supplementary Table 4). 12 patients with ages lesser than 1 and greater than 100 were filtered out of the clinical dataset, and the filtered data was sorted in order of increasing age. This was done using an R script and Microsoft Excel.

The OR calculations were performed in R, using epiR (v. 1.0-15) and epitools ( $v$ 0.510.1) packages. We used the epiR package for 2 by 2 OR calculation and epitools for multiple OR calculation. The Age versus Outcome plot was built with the construction of 2 by 2 tables for every age cutoff and then plotting every odds ratio as a single value. The OR values for Clade versus Outcome with comparison to the reference clade were calculated with epitools package. The reference clade was artificially created with the median value among all clades for the patient count and with the general outcome ratio for data split. For age group OR representation, we computed mean OR values for given age intervals. P-values are calculated from the chi-squared test. 


\subsection{CFR calculations}

The case fatality ratio (CFR) is used to measure the proportion of infected individuals with fatal outcomes. It estimates the percentage of deaths among identified confirmed cases. It is measured by the formula:

$$
C F R(\%)=N_{d p} / N_{p} \times 100
$$

where, $N_{d p}=$ number of deaths from disease, $N_{p}=$ number of confirmed cases

\section{RESULTS}

\subsection{OR calculations}

The Odds Ratio (OR) for a particular age range illustrates the odds that patients older than the specified age threshold are more likely to be at high risk.

After the cleaning step, the data contained 3608 individual patient records for subsequent analysis. OR analysis for the patient age groups highlights a trend towards being more exposed to the disease ( High risk) with higher age. In particular, the OR increased between the age range of $1-10$ (1.271) and 11-20 (1.313) but further decreased at age range 21-30 (1.290) before a progressive increase, with a first leap at the age range $61-70(2.465)$ and a second leap at the age range of 81-90 (8.977), representing the spiked value in the plot (Figure 2a). A decrease in the age range of 91100 (5.306) was then observed. (Figure 2a, Supplementary Table 2). The mentioned tendency is also shown for an individual age cutoff. (Supplementary Figure 1 )

OR values were obtained for individual clades (as stated in GISAID dataset) to test whether a risk is associated with the evolution of a virus. Descriptive analysis for known clades shows no significant age difference between them, except for GH and GR clades which showed significant $(P<.05)$ difference (Supplementary Figure. 2). On the contrary, the number of patients for each clade in a given country is now so consistent (Figure. 3 ). For the 11 countries with some patients above or equal to 100 (Supplementary Figure 3), Columbia, France, India, Saudi Arabia, and the USA had the most samples for the GH clade, China for the L clade. Moreover, Brazil, Russia, and Turkey for the GR clade, Singapore for $O$, and Spain for $G$ clades. The samples from $L$ clade are almost 
exclusively derived from China, whereas other patient counts per clade are distributed among all countries.

With regard to the reference, OR analysis was illustrated (Figure 2b). Further analysis between Individual pairwise Clade and OR analysis confirms the approach (Supplementary Figure 4). The highest OR value, compared to the base level, was the $L$ clade with a 1.58 estimate. Results for $G$ and $O$ clades are quite similar to 1.38 and 1.40 OR values, respectively. The lower limit of the $\mathrm{Cl}$ intervals (95\%) for all of the abovementioned clades ( $L, G$, and $O$ ) have OR values that are above 1, which indicates that the odds of being at High risk for the patients with virus clades $L, G$ and $O$ are higher than the base level. The pairwise OR calculation for $G$ and $S$ clades shows that their values are quite similar (Supplementary Figure 4 ). However, usage of a reference highlights a difference between them with an estimated 1.06 for $G$ clade and 0.82 for $S$ clade. On the other hand, the patient outcome for this clade is insignificant $(P>.05 ; 0.57$ and 0.28 for $\mathrm{G}$ and $\mathrm{S}$ clades respectively, and $\mathrm{Cl}$ (95\%) covers above and below 1). The clade, which is associated with the low-risk outcome for the patients is GR, which has 0.61 times low disease risk, with a 95\% confidence interval and true odds which lies between 0.48-0.76 $(P<.05)$. $\mathrm{V}$ clade has the widest $\mathrm{Cl}$ limits and a $P$-value of 0.7 .

To increase research reproducibility and for easy analysis, result exploration, and interpretation, an ORCaG (Odds Ratio Calculations for GISAID data) shiny application was created, which is available online at https://biopavlohrab.shinyapps.io/ORCaG/, and https://github.com/MountainMan12/GISAID phylo/tree/master/ORCaG. The application allows to dynamically change patient status category with the age cut-off for easy visual inspection of data. Documentation for the app is available at the corresponding GitHub page.

\subsection{CFR calculations}

In this study, the CFR for each age group was measured. The CFR had its peak in the age range of $90-100(26.8 \%)$ and the least at age 0-10 (0\%). The CFR for ages above 50 was about two times (or greater) more than that of ages below. This supports the fact that patients above 50 years are at a higher risk when compared to patients below 50 
years of age, though being at high risk doesn't confirm a death penalty. (Supplementary Table 3, Figure 6).

\subsection{Phylogenetic Analysis}

Phylogenetic analysis suggests the evolution of SARS-CoV-2. In the present study, more than 3500 genomes from 69 countries were analyzed, where the highest number of patients were observed corresponding to the GH clade for Indian samples (Figure 3). Upon tree visualization, a group of closely related Indian samples was clustered, the majority of which were classified as low-risk (Figure 4) corresponding to clade GH. In this cluster, no certain age relationship with the disease risk nor the clade type could be seen.

In another cluster of samples from Singapore, most of them showed high risk and corresponded to clade $\mathrm{O}$ with no special correspondence to a certain age group. (Figure 5). Figure 3 shows the samples from Singapore have the highest frequency of clade $O$.

\section{Age Distribution of Immunity Reaction}

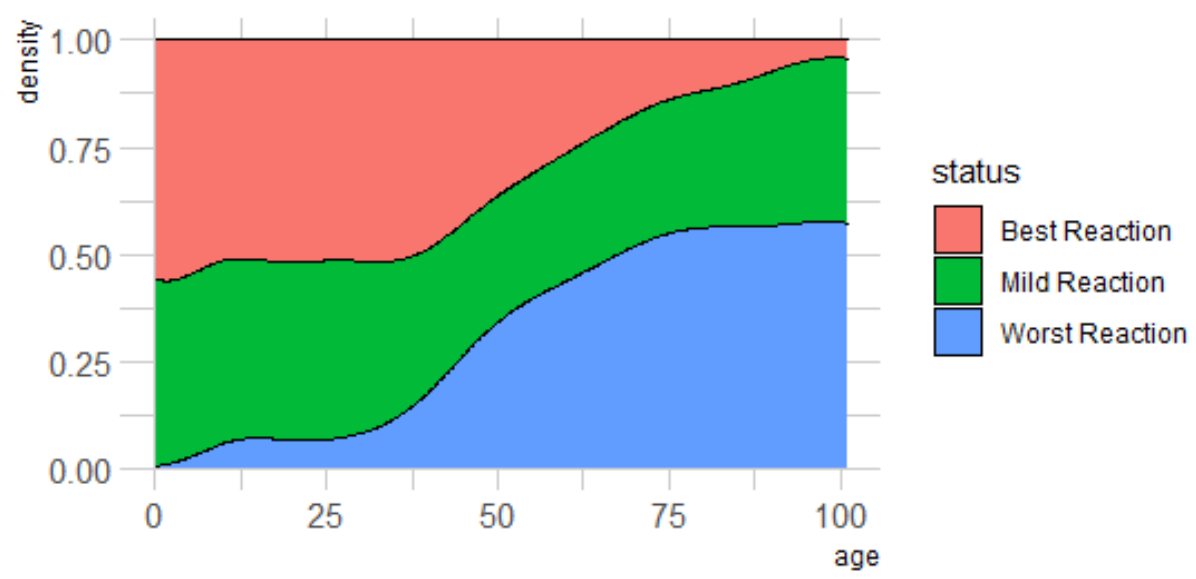

Figure 1: Age Distribution of Immunity reaction. The plot above shows the immunity reaction to the COVID-19 disease was best among the younger ones (mostly ages 25-50). 


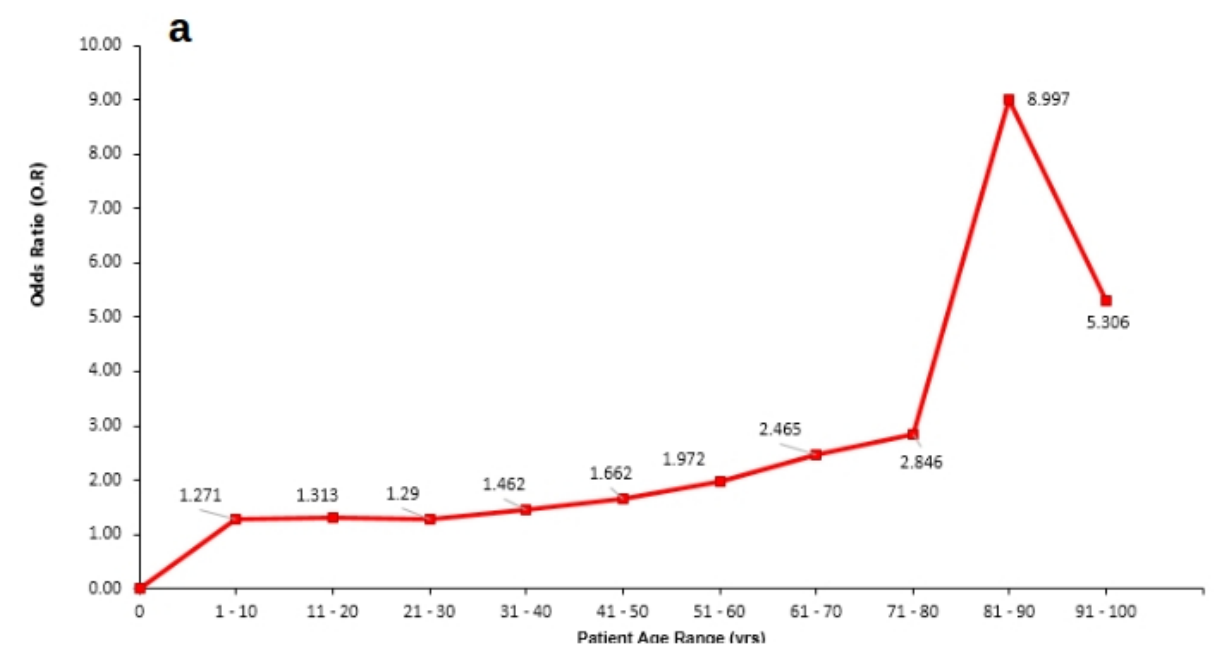

Odds ration of being at high risk given the Clade

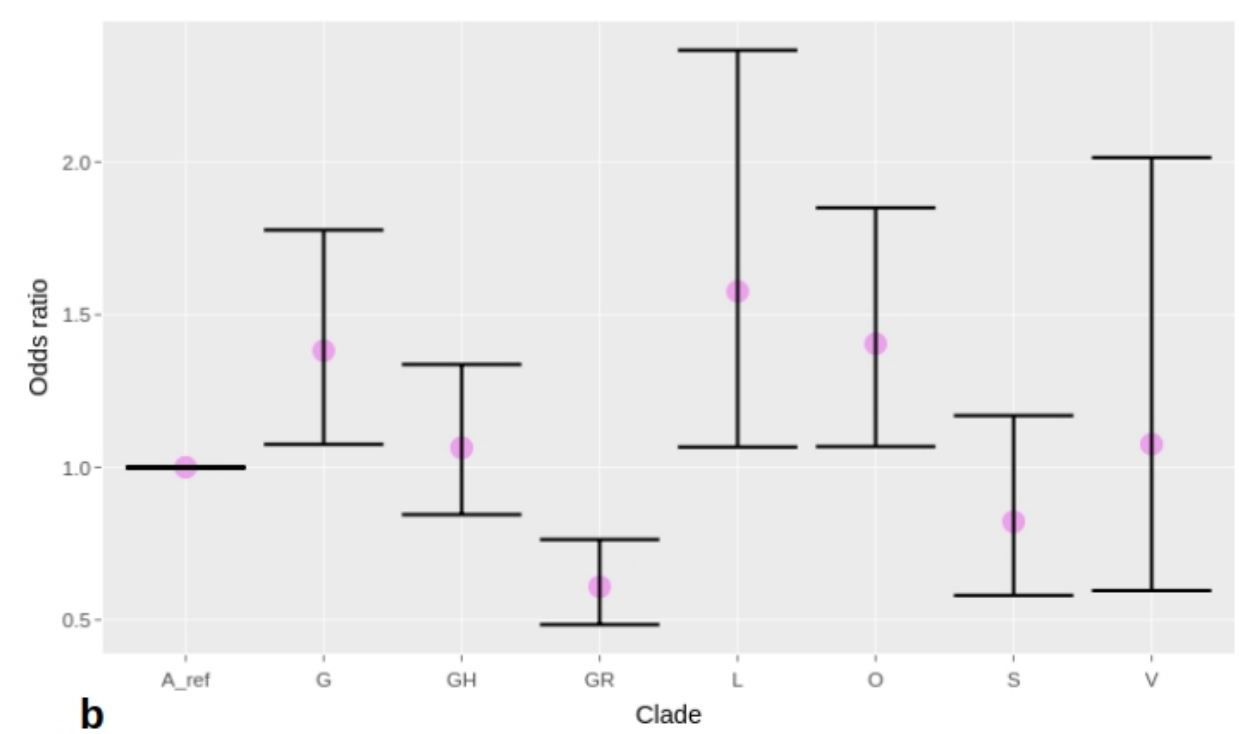

Figure 2: a) Odds Ratio plot showing Mean Age along with age groups. The $X$-axis shows the age groups at intervals of 10 years, while Y-axis shows the mean OR value within each interval. b) Odds ratio plot showing OR values for each clade. (Mean OR value is highlighted as a purple circle) 


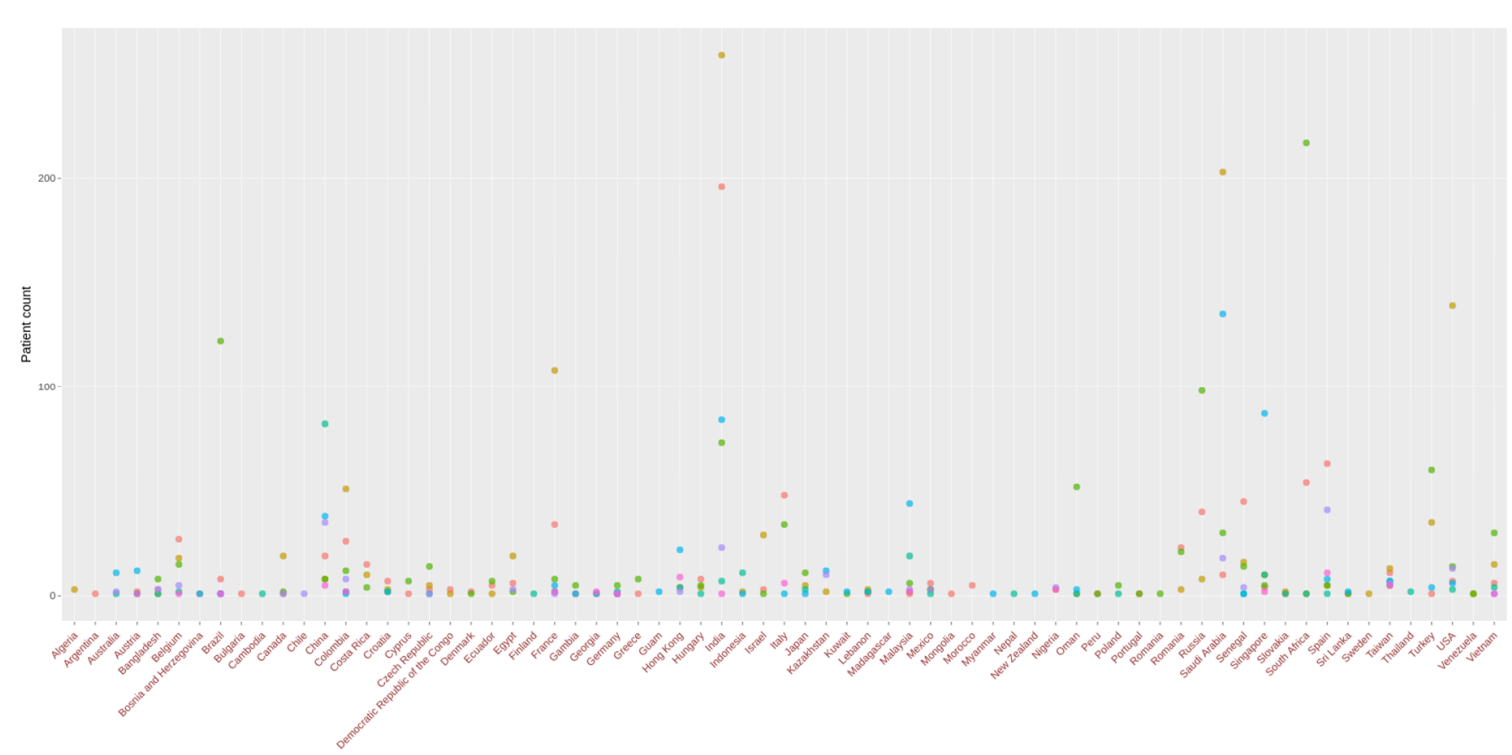

Figure 3: Clade distribution per country in the clinical dataset. The plot shows the highest frequency for Indian samples corresponding to the $\mathrm{GH}$ clade followed by $\mathrm{G}$ and $\mathrm{L}$ clades.

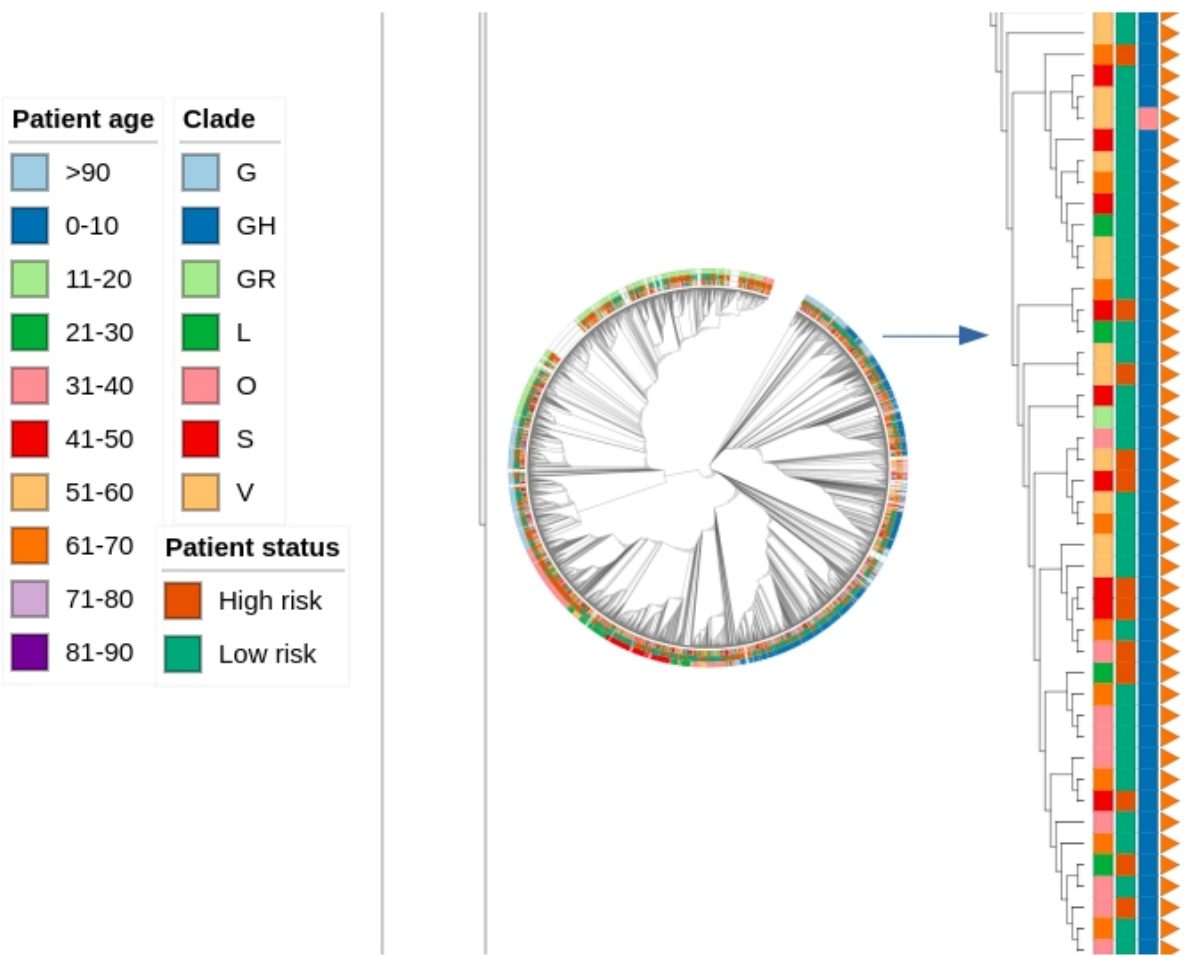

Figure 4: $\mathrm{iToL}$ visualization of the phylogenetic tree shows a group of closely related Indian samples, the majority of which show low-risk patients, characterized by clade $\mathrm{GH}$. Overall tree in circular view as visualized on http://itol.embl.de/shared/iTol 123. Annotations (from left): Column 1: Patient age, Column 2: Patient Status, Column 3: Clade, Column 4: Country (showing Indian samples [orange triangle]), 

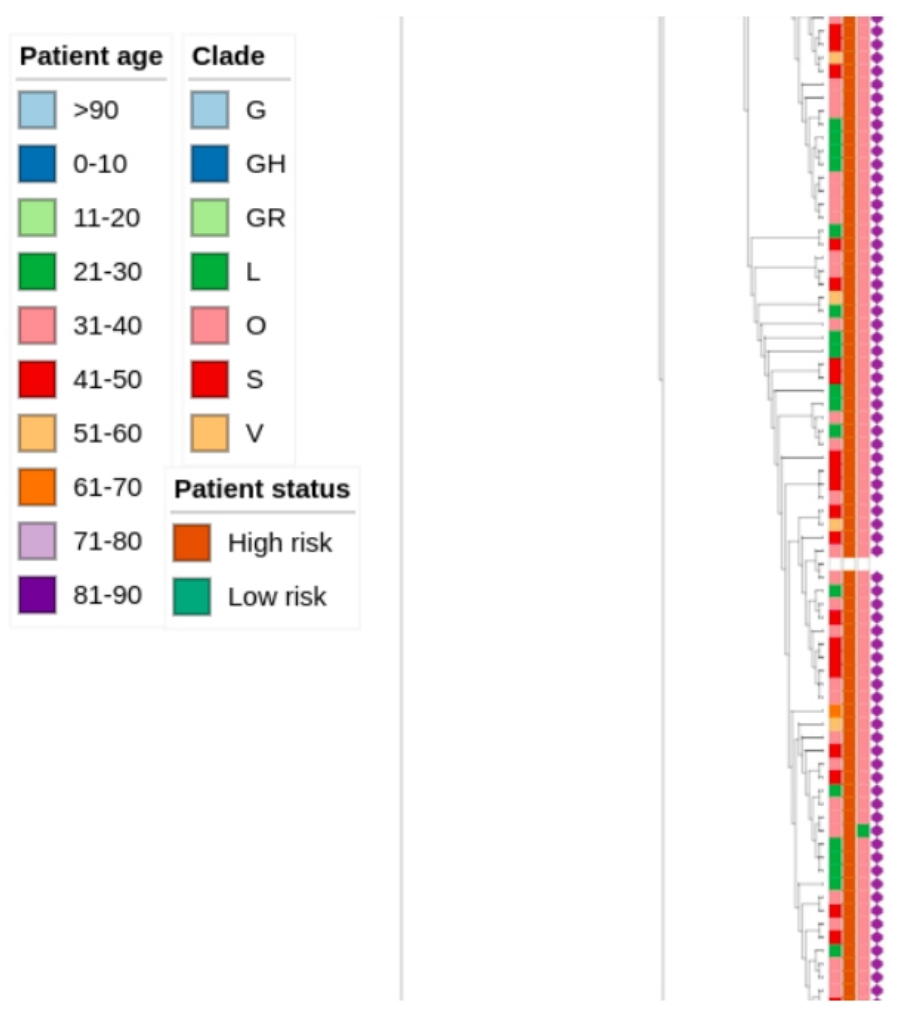

Figure 5: iToL visualization shows a group of closely related samples from Singapore which are classified as high risk across various age groups. This outcome could be attributed to genetic variations classified under clade $O$. NOTE: Annotations (from left): Column 1: Patient Age, Column 2: Patient Status, Column 3: Clade, Column 4: Country (showing Singaporean samples), The original branch lengths have been ignored.

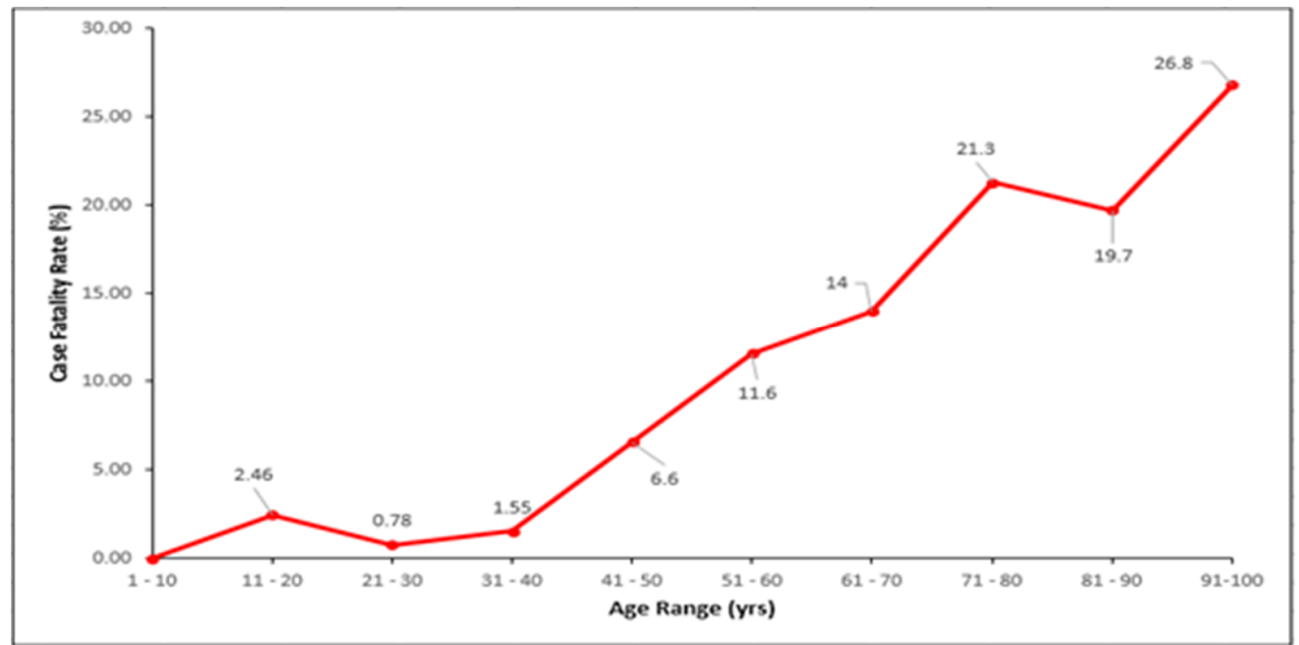

Figure 6: CFR plot showing CFR along with age groups. The $X$-axis shows the age groups at intervals of 10 years, while $Y$-axis shows the CFR value within each interval.

\subsection{Immunity reaction}


Additionally, an immunity reaction distribution plot of COVID-19 across all ages given in the dataset was generated (Figure 1) which shows that the immunity reaction to COVID19 was optimal among the younger individuals(mostly ages $25-50$ years). The immunity reaction dataset based on patient reaction is provided in Supplementary Table 1.

\section{DISCUSSION}

Since the beginning of the disease outbreak, age has been a significant forecasting determinant of COVID-19 in patients [26]. In this study, immunity reaction to COVID-19 infection was analyzed across all ages of the study's dataset. It showed that the immunity reaction to COVID-19 was optimal among the younger individuals(mostly ages 25-50 years), declined after the age of 50 years, and the least reaction was seen in the age range from 75 to100 years. Our results support the fact that immunosenescence is characterized by reduced $B$ and $T$ cell numbers as well as responses. Moreover, COVID19 infection is characterized in many cases with lymphopenia (decreased lymphocytes numbers) which is much higher in the elderly than that of the young and middle-aged patients [27], this may worsen the immune response in the elderly than younger age groups. Taken together, age-associated immune remodeling, in company with other predisposing factors such as malnutrition, decreased physical activity, and associated chronic medical conditions among the elderly lead to the decreased immune response in the older age groups, elevating their susceptibility to infectious diseases and responsible for the severe clinical manifestations observed in older patients. In this line of thought, the previously mentioned mechanisms suggest the underlying worse prognosis in older patients with COVID-19 and to some extent explain our following results that might lead to further research.

An important characteristic of a novel infectious disease as COVID-19 is its severity and its ability to cause death. The World Health Organization (WHO) report in August 2020 on estimating mortality from COVID-19 recommended that "efforts should be made to calculate risk-group-specific estimates of fatality risk to have a better insight on the true patterns of fatality" [28]. In the present study, we measured the CFR for different age groups, and results showed that the death rate increases as age increases which agrees 
with the Center for Disease Control and Prevention (CDC) report comparing death rate ratios of different age groups to the 18-29 years age group [29]. A slight difference in CFR progression was seen at the ages range 11-20 and 81-90, this proves the theory that CFR calculated during an ongoing pandemic is conditional because some active cases may subsequently die after the time of the report leading to underestimation of the CFR of the report $[28,29]$.

So we measured another estimate for disease outcome, we calculated odds ratios (OR) for disease severity with different age groups (Supplementary Table 2). Our results are consistent with a study done on 17 million people in England, where more than $90 \%$ of COVID-19 related deaths were recorded among people over 60 years of age. Furthermore, those above 80 years had an about 40 -fold increased risk compared with those who are 51-60 years [30]. In the current study, the OR had its peak at age range 81-90 years which almost tripled that of patients within the age range of 71-80 years, this also agrees with an initial study conducted in Italy that described the mortality rate and risk factors for patients above 80 years [31]. This shows that patients above 80 years of age are at higher risk [32], which could be due to their inherent reduced immune capacities and resilience [31].

The phylogenetic analysis of the circulating clade in a country and its risk association along with specific age groups is necessary to identify the specific groups with the highest treatment-targeted priority. Our study identified seven clades with the most abundant one was the $\mathrm{GH}$ clade accounting for low disease risk and the highest count in Indian and Saudi-Arabian populations. Bartolini et al., [33] reported the clustering of $\mathrm{V}$ and $G$ clades from the European Union (EU) countries. However, in our present study, there was an expanded clustering of clades across the 69 countries. Clades $L$ and $O$ with the highest disease risk had the least pairwise OR when compared with the other 5 clades. GISAID genome sequence interspersed different non-G clades, located on the gene with distribution in different clades indicating repeated occurrence with no evolutionary advantage[34].

Interestingly and in contrast to our previous results, our phylogenetic tree visualization showed a deviation from the regular observed pattern of the relationship between advanced age ( $>50$ years) and high-risk disease outcomes. Clusters from 
Indian samples showed the prevalence of the low-risk clade $\mathrm{GH}$ across varying age groups. Also, clusters from Singapore showed the prevalence of the high-risk clade $O$ across all age groups. Changes in age-group-specific infection were earlier observed in a study, carried out in EU countries, showing changes in the age group of the most affected population from ages $>60$ to ages 20 - 29 over several months. The median infection age also was shown to have decreased from 54 years to 39 years in a space of 7 months [34]. The impact of several genetic variants can be suggested by the fact that the virus does not show similar mortality rates across different countries. The viral progression may vary in terms of the genetic makeup of an individual, and the outcomes may also be due to several other factors that influence treatment and patient care. This deviation suggests that further factors should be taken into account during performing a risk-group-specific analysis of the disease, it will provide a more accurate understanding of the mortality rates related to SARS-CoV-2.

\section{CONCLUSIONS}

We have successfully analyzed more than 3500 genomes of SARS-CoV-2 isolated from COVID-19 patients from different geographical locations and identified a positive association between patient age and COVID-19 disease severity.

This study has its limitations, and this includes working with small datasets. More genomes could increase our confidence in OR analysis results. Variation in the accessibility to treatment availability and facilities can also influence the patient outcome. In the context of the proposed hypothesis, it is not clear as to whether age could have a direct impact on mortality of the patients, but this could be better understood by looking at

other

clinical

factors.

\section{DATA AVAILABILITY}

All datasets used are provided in the Zenodo repository:

https://zenodo.org/record/4007666\#.X1tmwnYzavM

All scripts written for the analysis are provided in the GitHub repo:

https://github.com/MountainMan12/GISAID phylo 


\section{ACKNOWLEDGMENTS}

We thank all contributors in this research work for their expertise, collaborative effort, and assistance throughout all aspects of the study. We thank HackBio for providing an enabling environment and platform on which the research was successfully carried out. We are grateful to our mentor Sarah Carl for her advice and constant guidance during the research work.

We gratefully acknowledge the authors, originating and submitting laboratories of the sequences from GISAID EpiCoV ${ }^{\mathrm{TM}}$ database on which the research was based. A table of the contributors is available in Supplementary Table 5 (GISAID acknowledgment table). We also thank the Galaxy Project which enabled us to carry out the analysis efficiently.

\section{CONFLICTS OF INTEREST}

The authors declare no conflict of interest

\section{REFERENCES}

1. Ayukekbong, J.A., Ntemgwa, M.L., Ayukekbong, S.A., Ashu, E.E., and Agbor, T.A. (2020). COVID-19 Compared to other Epidemic Coronavirus Diseases and the Flu. World Journal of Clinical Infectious Diseases. 10(1):1-13. DOI: $\underline{10.5495 / \text { wjcid.v10.i1.1 }}$

2. Čivljak, R., Markotić, A., and Kuzman, I. (2020). The Third Coronavirus Epidemic in the Third Millennium: What's Next?. Croatian Medical Journal. 61(1):1-4. DOI: $\underline{10.3325 / \mathrm{cmi} .2020 .61 .1}$

3. Peeri, N.C., Shrestha, N., Rahman, M.S., Zaki, R., Tan, Z., Bibi, S., Baghbanzadeh, M., Aghamohammadi, N., Zhang, W. and Haque, U. (2020). The SARS, MERS, and Novel Coronavirus (COVID-19) Epidemics, the Newest and Biggest Global Health Threats: What Lessons Have We Learned?. International Journal of Epidemiology. 49(3):717-726. DOI: 10.1093/ije/dyaa033

4. Mclntosh, K., and Perlman, S. (2015). Coronaviruses, Including Severe Acute Respiratory Syndrome (SARS) and Middle East Respiratory Syndrome (MERS). Mandell, Douglas, and Bennett's Principles and Practice of Infectious Diseases. 1928-1936.e2. DOI: 10.1016/B9781-4557-4801-3.00157-0

5. Petrosillo, N., Viceconte, G., Ergonul, O., Ippolito, G., and Petersen, E. (2020). COVID-19, SARS, and MERS: Are They Closely Related?. Clinical Microbiology and Infection. 26(6):729-734. DOI: $10.1016 /$ j.cmi.2020.03.026 
6. Zhu, N., Zhang, D., Wang, W., Li, X., Yang, B., Song, J., Zhao, X., Huang, B., Shi, W., Lu, R., Niu, P., Zhan, F., Ma, X., Wang, D., Xu, W., Wu, G., Gao, G.F., Tan, W. (2020). China Novel Coronavirus Investigating and Research Team. A Novel Coronavirus from Patients with Pneumonia in China, 2019. New England Journal of Medicine. 382:727-733. DOI: 10.1056/NEJMoa2001017.

7. Wu, F., Zhao, S., and Yu, B. (2020). A New Coronavirus Associated with Human Respiratory Disease in China. Nature. 579:265 - 269. DOI: 10.1038/s41586-020-2008-3

8.World Health Organization (WHO) Coronavirus disease (COVID-19): weekly epidemiological update.Geneva (WHO); 07 September 2020. Available from https://www.google.com/url?q=https://www.who.int/docs/default source/coronaviruse/situation-reports/20200907-weekly-epi-update4.pdf?sfvrsn\%3Df5f607ee 2\&sa=D\&ust=1599538538578000\&usg=AFQjCNEsaB84WSIVv5 vpJ2qu2MpQ78LXsg. Accessed on 8th of September 2020.

9.Elbe, S., and Buckland-Merrett, G. (2017) Data, disease, and diplomacy: GISAID's innovative contribution to global health. Global Challenges, 1:33-46. DOI:10.1002/gch2.1018 PMCID: $\underline{31565258}$

10. Siarhei, A.D., and Yury, K.K. (2020). SARS - CoV - 2: Structural diversity, phylogeny, and potential animal host identification of spike glycoprotein. Journal of Medical Virology. 92(9):1690-1694. DOI: 10.1002/jmv.25976.

11. Sheikh, J. A., Singh, J., Singh, H., Jamal, S., Khubaib, M., Kohli, S., Dobrindt, U., Rahman, S. A., Ehtesham, N. Z., \& Hasnain, S. E. (2020). Emerging genetic diversity among clinical isolates of SARS-CoV-2: Lessons for today. Infection, genetics, and evolution: journal of molecular epidemiology and evolutionary genetics in infectious diseases, 84, 104330. https://doi.org/10.1016/j.meegid.2020.104330

12. Koyama, T., Platt, D., Parida, L. (2020) Variant analysis of SARS-CoV-2 genomes. Bulletin of the World Health Organization 2020;98:495-504. DOI: http://dx.doi.org/10.2471/BLT.20.253591

13. Zhu, N., Zhang, D., Wang, W., Li, X., Yang, B., Song, J., et al. (2020) A novel coronavirus from patients with pneumonia in China, 2019. New England Journal of Medicine. $N$ Engl $J$ Med 2020; 382:727-733. DOI: 10.1056/NEJMoa2001017

14. Ji, W., Wang, W., Zhao, X., Zai, J., Li, X. (2020) Cross-species transmission of newly identified coronavirus 2019-nCoV. J Med Virol. 2020; 92:433-440

15. Yamada, K. D., Tomii, k., and Katoh, K. (2016). Application of MAFFT sequence alignment program to large data-re-examination of the usefulness of chained guide trees. $\begin{array}{llll}\text { Bioinformatics (Oxford, 32(21), } & \text { 3246-3251. }\end{array}$ https://doi.org/10.1093/bionformatics/btw412 
16. Tan, G., Gil, M., Loytynoja, A. P., Goldman, N., and Dessimoz, C. (2015). Simple chained guide trees give poorer multiple sequence alignments than inferred trees in simulation and phylogenetic benchmarks. Proceedings of the National Academy of Sciences of the United States of America, 112(2), E99-E100. https://doi.org/10.1073/pnas.1417526112

17. Wei, M., Yuan, J., Liu, Y., Tao Fu, T., Yu, X., Zhang, Z. (2020) Novel Coronavirus Infection in Hospitalized Infants Under 1 Year of Age in China. JAMA. 2020;323(13):13131314. DOI:10.1001/jama.2020.2131

18. Wang, D., Hu, B., Hu, C., Zhu, F., Liu, X., Zhang, J., Wang, B., Xiang, H., Cheng, Z., Xiong, Y., Zhao, Y., Li, Y., Wang, X., Peng, Z. (2020). Clinical Characteristics of 138 Hospitalized Patients With 2019 Novel Coronavirus-Infected Pneumonia in Wuhan, China. JAMA. 2020;323(11):1061-1069. DOI:10.1001/jama.2020.1585

19. Wes McKinney. Data Structures for Statistical Computing in Python. Proceedings of the 9th Python in Science Conference, 51-56 (2010)

20. Cock PA, Antao T, Chang JT, Chapman BA, Cox CJ, Dalke A, Friedberg I, Hamelryck T, Kauff F, Wilczynski B, and de Hoon MJL (2009) Biopython: freely available Python tools for computational molecular biology and bioinformatics. Bioinformatics, 25, 1422-1423

21. Katoh, K., Misawa, K., Kuma, K., and Miyata, T. (2002) MAFFT: a novel method for rapid multiple sequence alignment based on fast Fourier transform. Nucleic Acid Res., 30:30593066

22. Price, Morgan N., and Dehal, Paramvir S. and Arkin, Adam P. (2010). FastTree 2 â Approximately Maximum-Likelihood Trees for Large Alignments. In PLoS ONE, 5 (3), pp. e9490. DOI:10.1371/journal.pone.0009490

23. Blankenberg, D., Coraor, N., Von Kuster, G., Taylor, J., Nekrutenko, A. and The Galaxy Team. (2011) Integrating diverse databases into a unified analysis framework: a Galaxy approach. Database (Oxford):bar011. DOI:10.1093/database/bar011.

24. Letunic, I., \& Bork, P. (2019). Interactive Tree Of Life (iTOL) v4: recent updates and new developments. Nucleic acids research, 47(W1), W256-W259.

25. Szumilas M. (2010) Explaining Odds Ratios. J Can Acad Child Adolesc Psychiatry. 19(3): 227-229.

26. Bonanad, C., García-Blas, S., Tarazona-Santabalbina, F., Sanchis, J., BertomeuGonzález, V., Fácila, L., Ariza, A., Núñez, J., \& Cordero, A. (2020). The Effect of Age on Mortality in Patients With COVID-19: A Meta-Analysis With 611,583 Subjects. Journal of the American Medical Directors Association. 21(7), pages 915-918 DOI: https://doi.org/10.1016/j.jamda.2020.05.045 
27. Liu, K, Chen, Y, Lin, R, Han, K. Clinical features of COVID-19 in elderly patients: A comparison with young and middle-aged patients. J Infect. 2020;80(6):e14-e18. DOI:10.1016/j.jinf.2020.03.005

28. World Health Organisation, WHO. (2020). Estimating mortality from COVID-19. Scientific brief. https://www.who.int/news-room/commentaries/detail/estimating-mortality-from-covid$19 \#$

29. Center for Disease Control and Prevention (2020). Coronavirus Disease 2019 (COVID19): COVID-19 Hospitalization and Death by Age.https://www.cdc.gov/coronavirus/2019ncov/covid-data/investigations-discovery/hospitalization-death-by-age.html

30. Williamson, E. J., Walker, A. J., Bhaskaran, K., Bacon, S., Bates, C., Morton, C. E., Curtis, H. J., Mehrkar, A., Evans, D., Inglesby, P., Cockburn, J., McDonald, H. I., MacKenna, B., Tomlinson, L., Douglas, I. J., Rentsch, C. T., Mathur, R., Wong, A. Y. S., Grieve, R., ... Goldacre, B. (2020). OpenSAFELY: factors associated with COVID-19 death in 17 million patients. Nature. 584, pages 430-436 DOI: https://doi.org/10.1038/s41586-020-2521-4

31. Porcheddu R., Serra C., Kelvin D., Kelvin, N., and Rubino, S. (2020) Similarity in case fatality rates (CFR) of COVID-19/SARS-COV-2 in Italy and China. Journal of Infection in Developing Countries. 14 (2), pages 125-128. DOI: https://doi.org/10.3855/jidc. 12600

32. Worldometer (13th May 2020). Coronavirus Age, Sex, Demographics (COVID-19). Accessed 27th August 2020 from https://wwwworldometersinfo/coronavirus/coronavirus-agesex-demographics

33. Bartolini, B., Rueca, M., Gruber, C., Messina, F., Carletti, F., Giombini, E., Inpatient Di Caro, A. (2020). SARS-CoV-2 Phylogenetic Analysis, Lazio Region, Italy, February-March 2020. Emerging Infectious Diseases, 26(8), 1842-1845. https://dx.doi.org/10.3201/eid2608.201525.

34. Coronavirus disease 2019 (COVID-19) in the EU/EEA and the UK -eleventh update, 10 August 2020.Stockholm: ECDC; 2020. 


\section{APPENDIX}

Supplementary Table 1: Data Assignment Used In Immunity Reaction Plot (Figure 1)

\begin{tabular}{|c|c|}
\hline Initial & Assigned \\
\hline Alive & Best Reaction \\
\hline Deceased & Worst Reaction \\
\hline Live & Best Reaction \\
\hline Death & Worst Reaction \\
\hline Home & Best Reaction \\
\hline Recovered & Best Reaction \\
\hline Released & Best Reaction \\
\hline Cured & Best Reaction \\
\hline Hospitalized & Mild Reaction \\
\hline Quarantine & Best Reaction \\
\hline Recovering & Best Reaction \\
\hline Discharged & Best Reaction \\
\hline Pneumonia & Mild Reaction \\
\hline Isolation & Best Reaction \\
\hline ICU & Worst Reaction \\
\hline Inpatient & Mild Reaction \\
\hline Outpatient & Best Reaction \\
\hline Symptomatic & Mild Reaction \\
\hline
\end{tabular}




\begin{tabular}{|c|l|}
\hline $\begin{array}{c}\text { Symptoms indicative of upper respiratory } \\
\text { infection }\end{array}$ & Mild Reaction \\
\hline EPHAD & Mild Reaction \\
\hline Bronchitis & Mild Reaction \\
\hline DAMA & Mild Reaction \\
\hline ICD-10 & Mild Reaction \\
\hline Asymptomatic & Best Reaction \\
\hline
\end{tabular}

Supplementary Table 2: Odds Ratio statistics calculated with https://biopavlohrab.shinyapps.io/ORCaG/

\begin{tabular}{|c|c|c|c|}
\hline AGE RANGE & MEAN OR & $\begin{array}{c}\text { MIN. OR IN } \\
\text { GROUP }\end{array}$ & $\begin{array}{c}\text { MAX. OR IN } \\
\text { GROUP }\end{array}$ \\
\hline $1-10$ & 1.271 & 1.030 & 1.549 \\
\hline $11-20$ & 1.313 & 1.131 & 1.399 \\
\hline $21-30$ & 1.290 & 1.145 & 1.379 \\
\hline $31-40$ & 1.462 & 1.328 & 1.589 \\
\hline $41-50$ & 1.662 & 1.586 & 1.749 \\
\hline $51-60$ & 1.972 & 1.822 & 2.179 \\
\hline $61-70$ & 2.465 & 2.271 & 2.670 \\
\hline $71-80$ & 2.846 & 2.564 & 3.357 \\
\hline $81-90$ & 8.977 & 4.216 & 19.729 \\
\hline $91-100$ & 5.306 & 0.971 & 13.740 \\
\hline
\end{tabular}


Supplementary Table 3: CFR calculations

\begin{tabular}{|c|c|c|c|}
\hline Range(yrs) & $\begin{array}{c}\text { Number of cases } \\
\mathbf{N}_{\mathbf{p}}\end{array}$ & $\begin{array}{r}\text { Number of patients } \\
\text { deceased } \mathbf{N}_{\mathrm{dp}}\end{array}$ & $\begin{array}{c}\text { Case fatality rate (\%) }= \\
\mathbf{N}_{\mathrm{dp}} / \mathbf{N}_{\mathbf{p}} \mathbf{x} \mathbf{1 0 0}\end{array}$ \\
\hline $1-10$ & 56 & 0 & $0.00 \%$ \\
\hline $11-20$ & 162 & 4 & $2.46 \%$ \\
\hline $21-30$ & 513 & 4 & $0.78 \%$ \\
\hline $31-40$ & 646 & 10 & $1.55 \%$ \\
\hline $41-50$ & 651 & 43 & $11.6 \%$ \\
\hline $51-60$ & 629 & 73 & $14.0 \%$ \\
\hline $61-70$ & 477 & 67 & $21.3 \%$ \\
\hline $71-80$ & 286 & 61 & $19.7 \%$ \\
\hline $81-90$ & 147 & 29 & $26.8 \%$ \\
\hline $91-100$ & 41 & 11 & \\
\hline
\end{tabular}


Supplementary Table 4: Patient status Assignment

\begin{tabular}{|c|c|}
\hline Deceased & High risk \\
\hline Released & High risk \\
\hline Alive & Low risk \\
\hline Asymptomatic & Low risk \\
\hline $\begin{array}{l}\text { Asymptomatic, identified as positive during the } \\
\text { preoperation investigation }\end{array}$ & Low risk \\
\hline Asymptomatic/Released & Low risk \\
\hline Bronchitis & High risk \\
\hline Cured & Low risk \\
\hline Death & High risk \\
\hline Deceased & High risk \\
\hline Discharged & High risk \\
\hline Discharged after recovery & High risk \\
\hline EHPAD_IRA & High risk \\
\hline Home & Low risk \\
\hline Hospitalized & High risk \\
\hline Hospitalized & High risk \\
\hline Hospitalized & High risk \\
\hline Hospitalized & High risk \\
\hline Hospitalized & High risk \\
\hline Hospitalized (Intensive care unit) & High risk \\
\hline Hospitalized in ICU & High risk \\
\hline Hospitalized or to be hospitalized & High risk \\
\hline Hospitalized, deceased & High risk \\
\hline Hospitalized, oxygen therapy, diarrhea & High risk \\
\hline Hospitalized, released & High risk \\
\hline Hospitalized/Deceased & High risk \\
\hline
\end{tabular}




\begin{tabular}{|c|c|}
\hline Hospitalized/Released & High risk \\
\hline Hospitalized; Stable & High risk \\
\hline Hospitalized, ICU, fully recovered & High risk \\
\hline $\begin{array}{l}\text { ICD-10 CODE: J20.9 - ACUTE BRONCHITIS, } \\
\text { UNSPECIFIED }\end{array}$ & High risk \\
\hline $\begin{array}{l}\text { ICD-10 Disease: J06.9 Acute upper respiratory infection, } \\
\text { unspecified }\end{array}$ & High risk \\
\hline $\begin{array}{l}\text { ICD-10 Disease: Z03.8 Observation for other suspected } \\
\text { diseases and conditions }\end{array}$ & Low risk \\
\hline $\begin{array}{l}\text { ICD-10 Disease: Z20.8 Contact with and exposure to } \\
\text { other communicable diseases }\end{array}$ & High risk \\
\hline $\begin{array}{l}\text { ICD-10 Disease: The tendency, J18.9 Pneumonia, } \\
\text { unspecified organism }\end{array}$ & High risk \\
\hline ICU & High risk \\
\hline ICU; Serious & High risk \\
\hline In-hospital & High risk \\
\hline Initially hospitalized, but now improved and discharged & High risk \\
\hline Intensive Care Unit & High risk \\
\hline Isolation & Low risk \\
\hline Live & Low risk \\
\hline Live & Low risk \\
\hline Live, acute respiratory infection & High risk \\
\hline Live, mild symptoms, at home & Low risk \\
\hline Live, physical examination & Low risk \\
\hline Mild & Low risk \\
\hline Mild / Contact exposure / Asymptomatic & Low risk \\
\hline Mild case & Low risk \\
\hline Mild clinical signs without hospitalization & Low risk \\
\hline Mild symptoms (fever, cardiovascular disorders) & Low risk \\
\hline Mild symptoms inpatient for observation & Low risk \\
\hline Mild, at home. & Low risk \\
\hline
\end{tabular}




\begin{tabular}{|c|c|}
\hline Mild/Contact exposure/Asymptomatic & Low risk \\
\hline Moderate / Outpatient & Low risk \\
\hline Moderate/Outpatient & Low risk \\
\hline Not Hospitalized & Low risk \\
\hline Not hospitalized & Low risk \\
\hline Outpatient & Low risk \\
\hline Pneumonia (chest X-ray) & High risk \\
\hline Quarantine & Low risk \\
\hline Quarantined & Low risk \\
\hline Recovered & Low risk \\
\hline Recovered and Released & Low risk \\
\hline Recovering & Low risk \\
\hline Released & High risk \\
\hline Released & High risk \\
\hline Released, Live & High risk \\
\hline Severe / ICU & High risk \\
\hline Severe/ICU & High risk \\
\hline Stable in quarantine & Low risk \\
\hline Still hospitalized & High risk \\
\hline Symptomatic & Low risk \\
\hline Symptoms indicative of upper respiratory infection & High risk \\
\hline Asymptomatic & Low risk \\
\hline Deceased & High risk \\
\hline Hospitalized & High risk \\
\hline hospitalized or to be hospitalized & High risk \\
\hline Inpatient & High risk \\
\hline Live & Low risk \\
\hline Outpatient & Low risk \\
\hline
\end{tabular}


Odds ratio of being at high risk given the age threshold

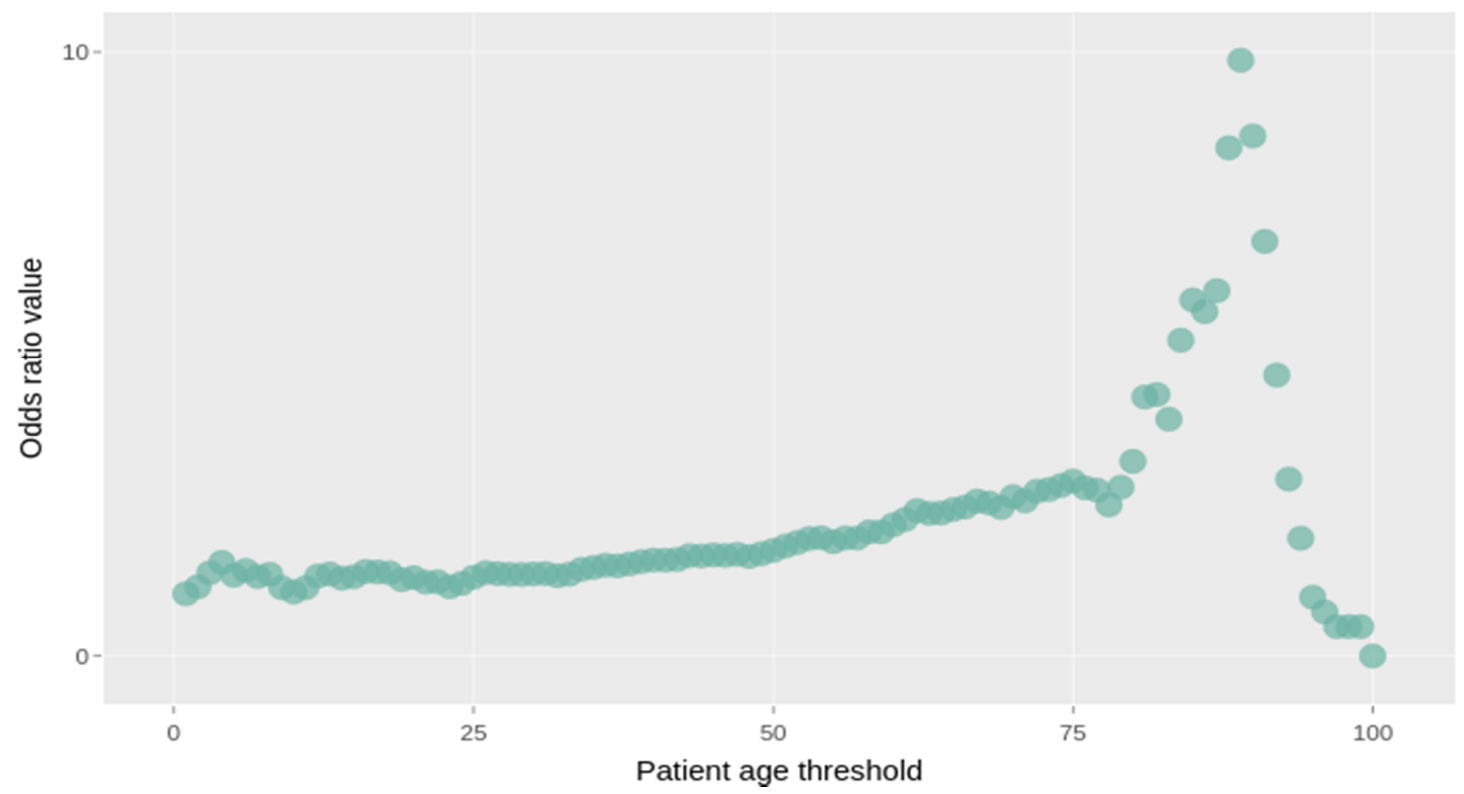

Suppl. Fig. 1. OR for an individual age threshold. The tendency of having a worse outcomes with being older is present here.

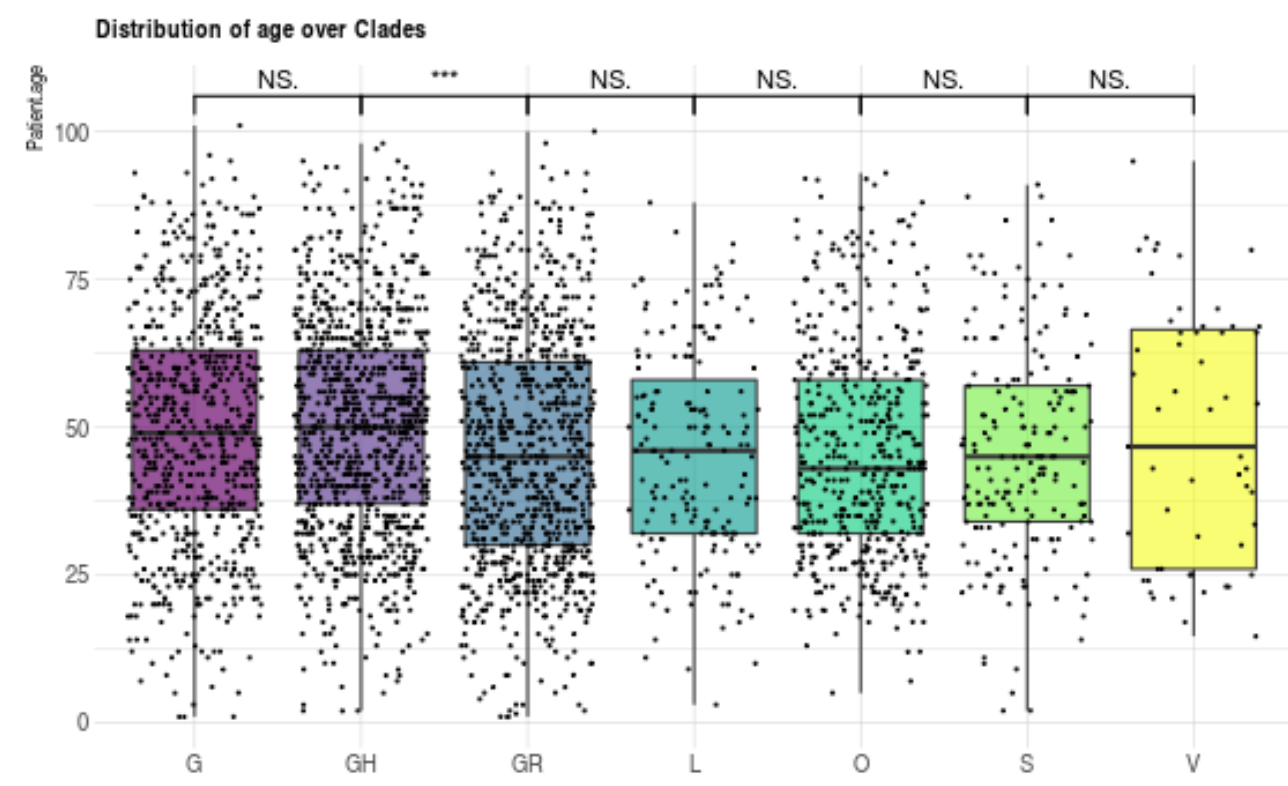

Suppl. Fig. 2 Age distribution over 7 SARS-Cov-2 clades. The only significant difference in age distribution is over $\mathrm{GH}$ and $\mathrm{GR}$ clades 


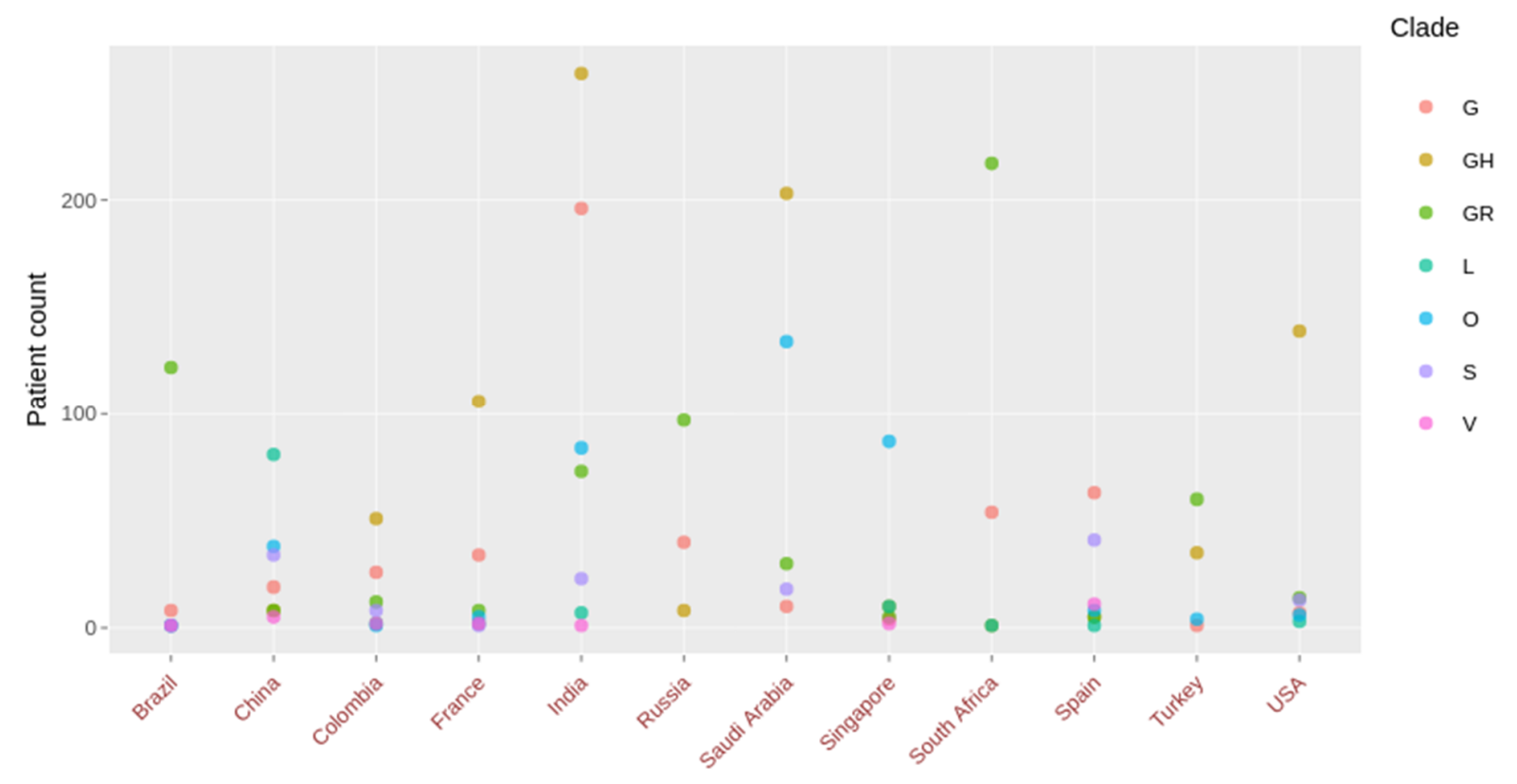

Suppl. Fig. 3 Patient count per clade for countries with more than 99 reported patient outcomes.

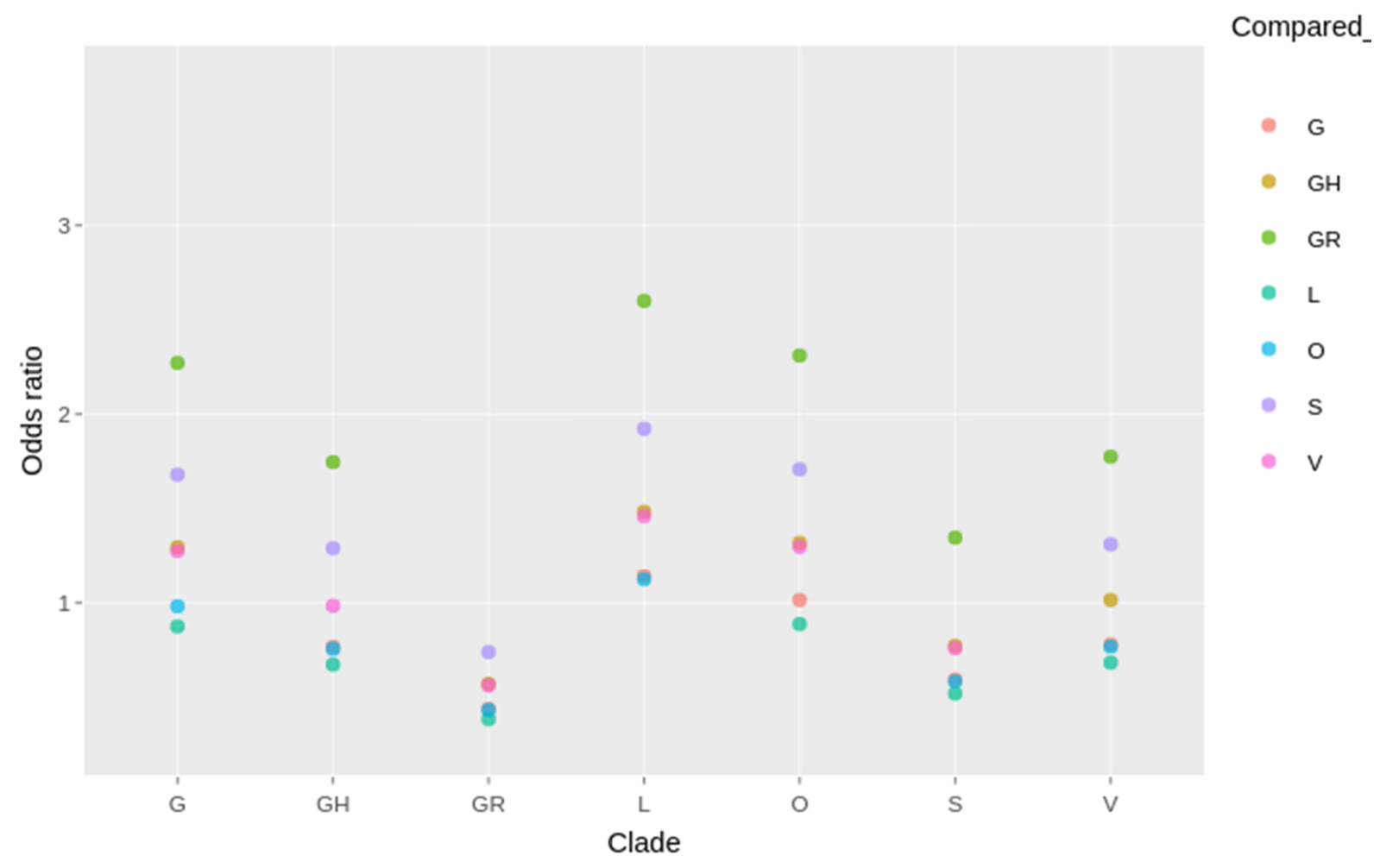

Suppl. Fig. 4 Pairwise OR calculations for clades versus each other. 